\title{
ETNOBIOLOGIA E DIÁLOGO INTERCULTURAL: CONCEPCCÕES DE PROFESSORES DE CIÊNCIAS E IMPLICAÇÕES PARA A FORMAÇÃO DOCENTE
}

\author{
ETHNOBIOLOGY AND INTERCULTURAL DIALOGUE: CONCEPTIONS OF \\ SCIENCE TEACHERS AND IMPLICATIONS FOR TEACHER TRAINING \\ Geane Machado ARAÚJO1*; Geilsa Costa Santos BAPTISTA²
}

\begin{abstract}
1.Graduanda de Licenciatura em Ciências Biológicas da Universidade Estadual de Feira de Santana, (UEFS), Bahia, Brasil, Grupo de Investigações em Ensino de Ciências (GIEEC), e-mail: geanemachadoaraujo@gmail.com; 2.Departamento de Educação, Universidade Estadual de Feira de Santana (UEFS), Bahia, Brasil; Programa de Pós-Graduação em Ensino, Filosofia e História das Ciências (PPGEFHC); Grupo de Investigações em Ensino de Ciências (GIEEC), email:geilsabaptista@gmail.com
\end{abstract} RESUMO: Apresentamos resultados de uma pesquisa qualitativa que teve por objetivo analisar as concepções de professores de ciências acerca da consideração da diversidade cultural por meio do diálogo intercultural, tendo a etnobiologia como coadjuvante para que isto aconteça e apontar possíveis implicações dessas concepções para o desenvolvimento da competência intercultural na formação docente. A coleta de dados se deu a partir de entrevista semiestruturada com quatro professoras de ciências naturais que atuam em escolas localizadas no município de Coração de Maria. Foram geradas cinco categorias temáticas e sobre elas análises de conteúdo, as quais indicam que as professoras participantes concebem como importante o diálogo intercultural, entretanto, elas apresentam limitações na compreensão dos termos cultura e ciência, além de não conhecerem a etnobiologia de modo a tê-la como subsídio ao ensino de ciências, o que o que pode dificultar a investigação, compreensão e relação entre diferentes saberes culturais nas salas de aula e, com isso, tornar-se um mediador cultural por meio do diálogo.

Palavras-chave: Etnobiologia, Formação de professores de ciências, Diversidade cultural

ABSTRACT: We present the results of a qualitative research that aimed to analyze the conceptions of teachers of sciences regarding the consideration of cultural diversity through intercultural dialogue, with the support of ethnobiology and to point out possible implications of these conceptions for the development of competences for intercultural education. Data collection took place from a semistructured interview with four teachers of natural sciences who work in schools located into the city of Coração de Maria. Five thematic categories were generated and developed content analysis about them, which indicates that the participating teachers conceive intercultural dialogue as important, however, they have limitations in understanding the terms culture and science, in addition to not knowing ethnobiology in order to have it as a support to science teaching, which can hinder the investigation, understanding and making relationship between different cultural knowledge in the classrooms and, thus, become a cultural mediator through dialogue.

Keywords: Ethnobiology, Teacher training, Cultural diversity

\section{INTRODUÇÃO}

Segundo Crepalde e Aguiar (2014), as escolas são espaços multiculturais, sendo preciso práticas pedagógicas que respeitem e valorizem os diversos sujeitos que não compartilham do padrão dominante de cultura ocidental. Dito em outras palavras, é preciso a adoção de estratégias educativas que possibilitem a interculturalidade com participações dos estudantes, auxiliando-os na atribuição de significados aos conteúdos ensinados, como partes que integram uma cultura específica, a cultura escolar (PIZZI e ALVES, 2010). Para Candau (2012), a interculturalidade no contexto escolar consiste das interações democráticas entre grupos culturais com reconhecimento e aceitação das diferenças.

No ensino de ciências, a interculturalidade é necessária para que haja sensibilidade à diversidade de saberes culturais relacionados ao mundo natural, sendo o diálogo uma importante estratégia para o estabelecimento de conexões entre as ciências e as vivências culturais dos estudantes. Freire (1987) define diálogo no campo da educação como um encontro entre seres humanos, num pensamento crítico, 
que solidarizam o refletir e o agir em processos comunicativos. Para Bohm (2013), o diálogo é o encontro no qual as pessoas ampliam as suas visões em conjunto, mas isto só é possível se houver predisposição mútua de ouvir uns aos outros, sem intolerâncias e discriminações, não importando as concordâncias e discordâncias.

De acordo com Suciu et al. (2014) quando o diálogo envolve diferentes culturas ele é nomeado de diálogo intercultural e ocorre num determinado espaço social, sendo condição necessária a abertura para compreensão por parte dos participantes, além da mediação de um profissional preparado.

Nas salas de aula de ciências, o diálogo precisa acontecer entre o professor e os estudantes, e entre os estudantes, sendo o professor um mediador cultural nesse processo. Para Teo (2013), o mediador cultural é o intercessor entre as culturas, aquele que busca gerar oportunidades para expressões dos pensamentos dos sujeitos com negociações dos seus significados culturais acerca das diferentes maneiras de compreender e explicar a natureza.

Todavia, para que o professor seja um mediador cultural durante o diálogo intercultural é preciso que ele se torne um investigador da sua própria prática pedagógica, como parte do seu processo formativo. Segundo Schön (1992), a investigação no contexto da formação dos professores está atrelada à reflexão e consiste na observação, na identificação de problemas, na análise e avaliação para reconstrução da ação didática. Essa investigação envolve, obviamente, os saberes que transitam nas escolas e o modo como as interações acontecem nas salas de aula, gerando elementos que melhorias aconteçam. Particularmente no sentido de implementar novas estratégias em função dos grupos e situações particulares (RAMÍREZ, 1995). Tudo isso termina por formar a competência intercultural do professor (DIMITROV e HAQUE, 2016) a qual, por sua vez, o torna sensível à diversidade cultural, no sentido de dar atenção, respeito e consideração pelas diferentes culturas que formam as escolas e seus espaços.

Gil-Pérez e Vilches (2005) destacam que a investigação e reflexão na formação do professor de ciências precisam envolver reflexões epistemológicas sobre a natureza da ciência, porque isso influenciará nas suas concepções e, de forma atrelada, nas suas práticas pedagógicas, as quais poderão interferir diretamente nas aprendizagens dos estudantes (VILELA-RIBEIRO e BENITE, 2009). Especificamente com relação ao diálogo intercultural, essas reflexões necessitam envolver as origens, significados, importâncias e contextos de aplicabilidades não apenas dos conhecimentos científicos, mas, também, dos conhecimentos que são levados pelos estudantes para as salas de aula, que são produtos dos seus universos socioculturais (BAPTISTA, 2010). Abd-El-Khalick e Lederman (2000) destacam que abordagens da história e da filosofia da ciência (ciência ocidental) no ensino e formação de professores de ciências contribuem significativamente para a compreensão da natureza da ciência, porque engaja os estudantes no modo como ela opera em determinadas épocas, além de outros aspectos.

De forma paralela à história e filosofia da ciência, a etnobiologia, uma ciência que investiga os inúmeros conhecimentos resultantes das relações entre as sociedades humanas e os demais seres vivos (POSEY, 1997), pode trazer ricas contribuições para a formação de professores e o ensino de ciências, auxiliando esses profissionais a investigar e compreender como os estudantes, dentro dos seus universos socioculturais, conhecem e se relacionam com o mundo vivo ao seu redor, seja através das suas publicações e/ou através dos seus procedimentos teóricos metodológicos, e disto gerar estratégias para o diálogo intercultural nas salas de aula (BAPTISTA, 2015).

De acordo com Sercu (2006), para compreender a competência intercultural do professor é preciso investigar os seus processos de pensamento, pois isto permite compreender as suas crenças e influências que podem exercer nas suas práticas pedagógicas, bem como na implementação de inovações didáticas. As concepções dos professores agem como filtros e afetam a maneira como eles percebem o ensino e a maneira como podem acomodar novos objetivos, pois existe uma relação razoavelmente clara entre as crenças dos professores e as suas práticas. Assim, por considerarmos a importância da investigação das concepções dos professores para compreensão do desenvolvimento da competência intercultural docente e, por conseguinte, da formação docente sensível a diversidade cultural, foi que pontuamos o seguinte questionamento: Quais as concepções dos professores de ciências no que tange à consideração da diversidade cultural por meio do diálogo intercultural nas salas de aula e como a etnobiologia poderia lhes auxiliar?

No presente trabalho apresentamos e discutimos os resultados da pesquisa de Iniciação Científica (IC) da primeira autora, desenvolvida com bolsa CNPq junto a Universidade Estadual de Feira de Santana (UEFS), tendo a segunda autora como orientadora (Edital PIBIC-UEFS-IC número 01/2018). O objetivo da pesquisa foi analisar as concepções de professores de ciências acerca da 
consideração da diversidade cultural por meio do diálogo intercultural tendo a etnobiologia como coadjuvante e apontar possíveis implicações dessas concepções para o desenvolvimento da competência intercultural na formação docente que seja sensível a diversidade cultural. Entendemos a competência intercultural na formação do professor como o conjunto de conhecimentos, habilidades e atitudes necessárias para a promoção do diálogo entre as culturas dos estudantes e a cultura científica que faz parte da cultura escolar, as quais são representadas nas salas de aula de ciências (componente curricular escolar).

\section{METODOLOGIA}

\section{Abordagem da pesquisa e sujeitos participantes}

A pesquisa ora apresentada teve abordagem qualitativa (CRESWELL, 2010), foi realizada entre os meses de julho de 2018 a julho de 2019, na sede do município de Coração de Maria - Ba e no Retiro, que é um dos seus distritos, especificamente em duas escolas da rede pública de ensino, que atendam estudantes agricultores e ou filhos de agricultores. Priorizamos tais instituições devido ao fato de que elas fazem parte de uma pesquisa mais ampla intitulada "A etnobiologia, a história e a filosofia das ciências na formação de professores de ciências para a diversidade cultural: estudo comparativo entre Brasil e Portugal", o qual constitui um subprojeto do projeto com aprovação CONSEPE-UEFS número 48/2004, e teve aprovação pelo Comitê de Ética em Pesquisa Envolvendo Seres Humanos (CEP-UEFS), com parecer número 1.007.254, em 26/03/2015. A referida pesquisa envolve estudantes provenientes de comunidades tradicionais, os quais mantêm seus saberes culturalmente ligados à natureza.

Nossa pesquisa envolveu quatro professoras de ciências naturais (Educação Infantil e Fundamental I) com formação acadêmica em pedagogia. Todas as pedagogas entrevistadas possuem pós-graduação em suas formações acadêmicas, a professora 1 em Ensino da Arte, a professora $2 \mathrm{em}$ Educação infantil e Psicopedagogia em andamento, a professora 3 possui especialização em educação infantil, e professora 4 possui pós graduação em Gestão de pessoas.

Justificamos a escolha dessas professoras primeiramente pelo fato de que o projeto mais amplo que deu origem a pesquisa ora apresentada estar direcionado aos professores de ciências dos níveis Fundamental e Médio, sendo que um estudo com este último nível já foi desenvolvimento dentro de outro projeto de iniciação científica da UEFS, também sob a orientação da segunda autora. A referida pesquisa aconteceu com professores de biologia e os resultados indicam que esses professores concebem como importante a consideração da diversidade cultural, embora existam dificuldades que remetem às suas formações inicial e/ou continuada, particularmente com relação às abordagens e relações entre a etnobiologia, história e filosofia da ciência e diálogo intercultural no ensino de biologia (BISPO e BAPTISTA, 2019). Segundo porque, concordando com Viecheneski e Carletto (2013), educar cientificamente nas escolas desde a infância constitui ação fundamental para ampliação das possibilidades de construção de sociedades democráticas, economicamente produtivas e mais sustentáveis, sendo condição necessária a formação de professores para esta finalidade com apoio institucional e implementação de políticas públicas para os docentes que atuam nos anos iniciais do Ensino Fundamental.

\section{Coleta e análise dos dados}

Inicialmente realizamos visitas a quatro escolas públicas localizadas na sede do município de Coração de Maria, Bahia, com intuito de apresentar a pesquisa e convidar os professores a participarem. No entanto, conseguimos a participação de apenas uma dessas escolas, pois as demais apresentaram as seguintes justificativas: uma atende apenas a educação infantil e nossa pesquisa pretendia $o$ envolvimento somente de professores de ciências que atuam do $1^{\circ}$ ao $9^{\circ}$ ano do ensino fundamental; outra informou que será fechada e a última argumentou que não participaria porque sofreu várias modificações nos últimos meses, entre elas a falta de professor de ciências na instituição, o que inviabilizaria a realização de entrevistas.

Em seguida, realizamos visitas na escola do Retiro, que possui o ensino fundamental. Primeiramente conversamos com a direção e com os professores apresentando a proposta da pesquisa e percebemos que lá apenas uma professora possui formação acadêmica em Pedagogia e leciona a disciplina ciências, a qual contribuiu para o estudo participando da entrevista.

Com intuito de apresentar a pesquisa aos participantes e assegurar as suas integridades e dignidades dentro dos padrões éticos das pesquisas envolvendo seres humanos (BRASIL, 2012), 
entregamos um Termo de Consentimento Livre e Esclarecido (TCLE) para as direções das escolas e para as professoras que, após leitura, assinaram o referido termo concordando com suas participações.

O próximo passo foi a realização de entrevista semiestruturada com as pedagogas, professoras de ciências participantes, para a identificação das suas concepções com relação à temática formação docente e ensino para a diversidade cultural. As seguintes questões compuseram nosso protocolo de questões: 1. Qual a tua formação na graduação? 2. Possui alguma pós-graduação? 2. Para você, o que é ciência? 3. O que é cultura? 3. Você considera importante a consideração dos saberes culturais dos estudantes nos momentos de ensino? Justifique tua resposta. 4. O que significa etnobiologia? 5. Você acredita que os professores de ciências estão preparados para lidar com a diversidade cultural da escola?

Para garantir as privacidades dos sujeitos, as suas respostas foram identificadas por P1, para a primeira resposta transcrita, $\mathrm{P} 2$, para a segunda transcrta, $\mathrm{P} 3$, para a terceira resposta transcrita e $\mathrm{P} 4$, para a quarta resposta transcrita.

As respostas dadas pelas professoras foram registradas com auxílio do gravador do Smartphone Samsung Galaxy A20 32GB ®, transcritas e organizadas em categorias temáticas (BARDIN 1977), no editor de texto Word ${ }^{\circledR}$. Dentro de cada categoria, as respostas foram discutidas à luz da literatura da área de educação, ensino de ciências e etnobiologia.

\section{RESULTADOS E DISCUSSÃO}

As entrevistas com as professoras participantes tiveram duração de sete a quatorze minutos, e a partir delas organizamos cinco categorias temáticas, a saber: (1) Importância dos saberes culturais dos estudantes; (2) Desconhecimento do termo Etnobiologia; (3) Formação docente para lidar com a diversidade cultural; (4) Cultura como atividade cotidiana dos indivíduos; e (5) Conceito de ciência como ciências, componente curricular escolar.

\section{Importância dos saberes culturais dos estudantes}

Para Vasconcelos et al. (2003), é necessária a consideração das concepções prévias dos alunos para a aprendizagem que tenha significados contextuais. Observamos que as concepções das professoras estão direcionadas com esta premissa, pois elas responderam que consideram como importante os conhecimentos prévios dos estudantes, como é possível evidenciar nas suas falas a seguir:

\section{P1: Sim, mas tem que ver quais são pra poder tá valorizando, né! Buscando trabalhar dentro da realidade deles também.}

P2: Acho muito importante porque assim hoje nós temos alunos de várias etnias, de várias culturas [...].

P3: É importante, acaba ajudando assim porque fica assim um aprendizado mais aproximado né [...].

P4: Muito, porque assim difere de um lugar pra outro... aqui eles têm mais essa questão da terra, do plantio, do cultivo... Então tem que respeitar porque o enfoque tem que ser diferenciado [...].

Além de reconhecer os saberes prévios como importantes, as professoras demonstram nas suas falas outras preocupações que estão relacionadas com a consideração desses conhecimentos. P1 ressalta a necessidade de investigação dos saberes culturais para que seja possível considerá-los nos momentos de ensino, o que está de acordo com os nossos referenciais para o ensino de ciências intercultural; P2 percebe a existência de várias culturas na sala de aula e P3 e P4 destacam a contextualização com forma de aproximação do ensino com a realidade vivenciada pelos estudantes.

Sobre a consideração dos conhecimentos prévios, concordamos com as professoras participantes da nossa pesquisa, pelo entendimento de que não basta apenas escutar os estudantes, mas, também, estabelecer relações entre os seus conhecimentos culturais e os conhecimentos científicos ensinados pelos professores, porque as salas de aula são espaços multiculturais, sendo a ciência uma das culturas que integram esses espaços (COBERN, 1994). A partir dessa compreensão, é necessário que o professor reflita como irá conduzir o ensino, buscando estratégias para relacionar as diferentes maneiras 
de compreender o mundo em prol de significações das aulas e, certamente, o diálogo é a melhor maneira para que isso ocorra.

O diálogo vai auxiliar os sujeitos na comunicação dos seus pensamentos acerca da temática que está sendo explorada na sala de aula. Nesse processo comunicativo, há consideração por parte dos interlocutores das razões de cada sujeito e sem tentativas de hierarquizações (LOPES, 1999). Os conhecimentos que integram as diferentes culturas são considerados e respeitados, porque há consciência da existência de diferentes formas de conhecer o mundo natural. Sendo assim, os estudantes ampliarão as suas visões de mundo, sendo capazes de fazer escolhas entre quais conhecimentos poderão utilizar diante de questionamentos e circunstâncias específicas das suas vidas (BAPTISTA, 2010).

\section{Desconhecimento do termo etnobiologia}

As respostas dadas pelas professoras para o significado da etnobiologia evidenciam pouco ou nenhum conhecimento, como podemos observar a seguir:

P1: Ai tu vai me explicar direitinho que eu quero saber, essa parte aí tu vai falar porque pegou um pouco pra mim.

\section{P2: Não sei.}

P3: Eu nunca ouvi falar não desse conceito não, mas eu acredito que é a biologia formada mais para a questão cultura, da cultura, do biológico que as vezes acaba tendo essa diferenciação né, corporal a depender da cultura ou do país, sei lá, alguma coisa assim.

P4: O que eu sei de etnobiologia é a questão étnica né! Trabalhar a biologia com os traços étnicos. Hoje infelizmente, pelo menos nos livros didáticos não é muito trabalhado isso não, os livros didáticos não se detém muito a isso por isso que o professor tem que tá antenado e tem que ver a realidade local pra trabalhar a questão cultural, porque hoje tanto a ciência quanto as outras disciplinas, olha o plano de curso é claro, mas às vezes tem conteúdos que eu insiro na minha sala de aula porque eu sei que tem a necessidade.

De acordo com Baptista e Araújo (2018, v. 12, p. 77), a etnobiologia é “[...] o estudo das relações entre os seres humanos e os demais seres vivos tendo as culturas como mediadoras desse processo". P1, P2 e P3 responderam claramente que desconhecem o termo etnobiologia. Já P4 conseguiu fazer uma aproximação com questões éticas, porém, não apresentou explicitamente as interações culturais no "Trabalhar a biologia com os traços étnicos". Apesar disto, P4 traz um aspecto interessante, que é a relação da biologia com as questões étnicas no ensino de biologia, particularmente nos livros didáticos.

O fato de a maioria das professoras não conseguirem definir o termo etnobiologia pode interferir nas suas práticas pedagógicas, especificamente nos momentos de investigação e compreensão dos saberes culturais. Porque, de maneira geral, falar que é importante considerar os saberes culturais dos estudantes é algo simples e que a maioria dos professores reconhece, como foi o caso dos professores de biologia (BISPO e BAPTISTA, 2019). No entanto, compreender como executar essa dinâmica em sala de aula pode ser um pouco mais difícil se o professor não tem acesso aos conhecimentos e recursos que podem ajudá-lo nesses momentos, como é objetivo das pesquisas etnobiológicas voltas para o ensino de ciências (BAPTISTA e ARAUJO, 2018). De acordo com Posey (1997), a etnobiologia auxilia na mediação entre as diferentes culturas, sendo pautada na compreensão e respeito entre os diferentes grupos sociais.

O conhecimento sobre a etnobiologia é importante para a profissão e formação docente, especialmente porque contribui para que os professores identifiquem e compreendam os saberes culturais dos estudantes, envolvendo-os no diálogo intercultural na sala de aula e, consequentemente, aprimore suas práticas pedagógicas, visto que a maneira como concebem o ensino e a aprendizagem interferem na forma metodológica como ensinam (BAPTISTA, 2015). 


\section{Formação docente para lidar com a diversidade cultural}

Sobre a preparação docente para lidar com a diversidade cultural presente na sala de aula, foi interessante notar que as professoras responderam que elas sentem preparadas:

P1: Eu acho que sim, né! Tem que buscar, tem que se preparar pra ser professor de ciências ou de qualquer área tem que tá preparado né [...].

P2: Eu acho que eles estão preparados, procurando cada vez mais se aprimorarem [...].

P3: Eu acredito assim, que [...] todos nós temos formação básica. Eu acho que tá, porque eu assim que a formação básica todos nós tivemos. Agora é assim, a gente nunca pode parar no conhecimento que a gente obteve no tempo de faculdade né, é questão de formação contínua mesmo [...]. Eu acho que tá na medida do básico sim, mas a necessidade de tá sempre atualizando é crucial.

\section{P4: Eu acho que os professores em si estão.}

Contrariamente ao que responderam, interpretamos nas respostas acima que as professoras não estão preparadas para lidar com a diversidade cultural, e isto porque há contradições nas suas falas, por exemplo de P1, quando ela ao mesmo tempo em que assume estar preparada diz que "[...] tem que se preparar pra ser professor de ciências". Embora haja contradição, isto parece-nos relevante para a formação da competência intercultural, pois demonstra preocupação com a necessidade de formação continuada e isto fica mais evidente na resposta de P4, que salienta a necessidade da formação continuada, que se expressa na busca pela preparação para além da formação da graduação, através da participação em cursos de formação continuada.

É possível que as professoras tenham se sentido inibidas diante do questionamento e respondido que se sentem preparadas porque reconhecem a importância do respeito e consideração das diferentes culturas se fazem presentes nas escolas, embora não estejam familiarizadas com estratégias que lhes auxiliem.

Para Canen e Xavier (2011), a formação inicial não é suficiente para que o professor seja sensível à diversidade cultural, mas o começo para as primeiras ações e com possíveis conflitos que possam surgir. De acordo com estas autoras, a formação docente para a diversidade cultural é contínua, acontece na prática pedagógica, no cotidiano escolar e pode motivar os estudantes para o convívio e tolerância em sociedade.

A P4 faz uma crítica ao espaço e gerência escolar afirmando que ambos não estão preparados para lhe dar com tal diversidade, como é perceptível em sua fala:

P4: Eu acho que os professores em si estão, eu acho que a escola, o todo é que não está porque assim as vezes os professores de ciências têm uma visão assim, a gente que trabalha ciência a gente precisa muito de recursos e a escola não tem, infelizmente não tem. As vezes a gente até adapta algumas coisas, sabe! Mas não tem, e as vezes quando a gente tenta falar ó vamos trabalhar isso de tal forma a escola, o todo da escola, quando eu falo o todo eu tô falando a direção, coordenação acha que são coisas banais, coisas que não [...] porque você não faz assim, passa no quadro, não sei o quê, não sei $o$ quê, então a gente fica frustrado, a verdade é essa a gente fica muito frustrado. Mas assim, o desafio o professor acho que tá preparado, o que não está preparado é o espaço escolar, não está preparado pra receber essas ideias que o professor vem trazendo.

A resposta acima é de extrema relevância se considerarmos a importância da participação efetiva de toda comunidade escolar para implementação de estratégias que facilitem a prática pedagógica em prol da diversidade cultural. Para $\mathrm{P} 4$ existem dificuldades, como o espaço e a gerência escolar que não dá suporte para o trabalho docente. O trabalho docente, de acordo com a nossa interpretação da fala de 
P4, é influenciado pela existência de divergências de opiniões acerca da importância de realização de atividades que promovam a valorização das diversas culturas presentes na escola. P4 diz pensar em alternativas para melhorias e reconhece que para colocá-las em prática é preciso atenção e reflexão, pois a escola é um espaço único e precisa estar em sintonia, no sentido de que aja a preocupação com os estudantes, com o espaço que eles frequentam e com recursos que devem ser utilizados para contribuir para uma educação melhor e inclusiva do diverso. Apesar de P4 apresentar entraves, entendemos que ela poderá ter sucesso nas suas tentativas, pois, segundo Baptista (2015), mesmo diante das dificuldades enfrentadas, é importante que o professor reconheça o problema como um passo para transformá-lo, claro, dentro das possibilidades situadas.

A resposta de P4 também é relevante porque pode auxiliar em reflexões sobre o ambiente escolar e a utilização dos seus recursos, e a partir daí possa contribuir com pesquisas futuras no intuito de verificar problemas e soluções para melhorias do trabalho docente e consequentemente para o ensino.

\section{Cultura como atividade cotidiana dos indivíduos}

Apesar de percebermos que as professoras concebem como importante a consideração da diversidade cultural no ensino de ciências e se sentirem preparados, inferimos como necessário que elas ampliem os seus conceitos sobre o termo cultura, pois quando foram questionadas sobre o seu significado elas apresentaram respostas pouco descritivas e direcionadas ao entendimento de que a cultura é algo individual. P3 concebe a cultura como uma produção humana, mas não argumenta qual seria essa produção e nem como ela acontece: "Cultura é toda a produção que a gente tem contato né, nós produzimos... Eu entendo cultura como uma produção mesmo, humana”. Já P1, P2 e P4 compartilham a concepção de cultura como sendo exclusivamente as atividades voltadas para a realidade cotidiana de cada indivíduo, através das relações familiares e sociais, como é perceptível em cada fala que a seguir:

P1: Cultura é tudo que faz parte da nossa vida cotidiana [...] cultura é tudo que faz parte do saber como a cultura da nossa cidade, do nosso município.

P2: Eu acho que cultura é você saber sobre tudo que lhe rodeia, é você buscar também mais conhecimentos, coisas desconhecidas que você não sabe que existe.

P4: [...] cultura é aquela bagagem que você traz desde quando você nasce, que são as impressões dos seus pais, da sua mãe, e às vezes nem só de pai e mãe porque tem crianças que, é a realidade daqui, que não convivem com pai e mãe, dos avós de quem os cria, então isso que é cultura.

O conceito de cultura que adotamos neste trabalho tem relação como a forma pela qual o sujeito interage e significa o mundo. Para Geertz (1989), cultura é um sistema de símbolos e significados nos termos dos quais as interações sociais ocorrem; culturas são significados produzidos pelos homens que orientam a existência. Dado este conceito, entendemos que os professores de ciências para promover o diálogo intercultural precisam pensar e conceber o termo cultura de maneira a englobar todos os aspectos da existência humana e suas relações com o mundo, incluindo aí aspectos como crenças, pensamentos, linguagens, entre outros que não são inerentes ao indivíduo, mas também ao grupo ao qual pertence. De igual forma, que as culturas não estão estagnadas no tempo, mas influenciam e recebem influências, dentro da mesma cultura e fora dela, provocando mudanças.

Importa ressaltar que apesar de indicarmos como necessária a ampliação das concepções das professoras para o termo cultura, reconhecemos que os conceitos que elas apresentaram não estão incorretos. Recomendamos que seus conceitos sejam ampliados, posto que isto poderá contribuir para as suas visões de mundo cultural e, a partir daí, melhorar suas práticas pedagógicas que estejam atentas e sensíveis aos diferentes saberes e práticas que são inerentes às diversas culturas.

\section{Conceito de ciência como ciências, componente curricular escolar}

A respeito do conceito do termo ciência, P1 não conseguiu responder, como é possível observar na sua resposta: "Pula, passa para a outra questão". Essa fala indica a falta de conhecimento sobre o significado do termo, ou mesmo insegurança da sua parte diante da pergunta. Já P2 não apresentou clareza na sua resposta, indicando apenas seu sentimento positivo quando ensina ciências, o que, a seu 
ver, é falar sobre a natureza: "A ciência é gostoso, amo trabalhar com ciência, mexer com a natureza, é descobrir novidades, é experiência, adoro". Ao nosso interpretar, ciência para P2 é o estudo da natureza.

As respostas dadas por P3 e P4 revelam uma compreensão de ciência como sendo apenas a ciência escolar (componente curricular Ciências): "Ciência eu entendo como ciência... é a ciência que estuda mais especificamente o corpo né, sobre o corpo, sobre o ambiente" (P3); "Ciências na verdade é o estudo de seres, sejam eles humanos ou não e toda a natureza, tudo que nos cerca porque abrange também ciências tecnológicas que também é uma ciência, então é tudo que está o nosso redor, tudo que envolve o ser humano" (P4).

Interpretamos que as concepções de P3 e P4 apresentam limitações, não apenas por fazer referência apenas à ciência escolar. A P3 restringiu o significado do termo ciência como o ensino do Corpo Humano e do Ambiente, como conteúdos curriculares e P4 e P4 faz referência explicita ao termo Ciências, definindo ciência como sendo o estudo dos seres vivos, incluindo também as tecnologias. Entendemos e adotamos aqui a concepção de ciência como uma cultura, a partir da definição trazida por Vogt (2003), de que a ciência é a cultura dos cientistas, a qual pode ser representada por um modelo de espiral que contém quatro quadrantes, nomeadamente "espiral da cultura científica". O referido espiral se inicia através da produção e difusão da ciência, seguindo para o segundo quadrante que está relacionado ao ensino de ciências. O terceiro quadrante traz o ensino para a ciência e o quarto, e último, aponta as atividades relacionadas a divulgação científica.

\section{CONSIDERAÇÕES FINAIS}

Embora não tenha sido propósito central deste trabalho, consideramos que nossos resultados coincidem com aqueles obtidos na pesquisa de Bispo e Baptista (2019) com professores de biologia. As professoras de ciências naturais que participaram da nossa pesquisa concebem como importante o diálogo intercultural nos momentos do ensino, entretanto, elas apresentam limitações na compreensão dos termos cultura e ciência, além de não conhecerem a etnobiologia de modo a tê-la como subsídio para investigação e compreensão dos saberes culturais dos estudantes.

Acreditamos que a etnobiologia é de suma importância para a formação do professor e consequentemente para o ensino de ciências, pois ela estuda exatamente a relação dos seres humanos com a natureza dentro dos seus universos socioculturais. Quando o professor desconhece esta ciência, incluindo aí seus procedimentos metodológicos e produtos (artigos científicos, textos, palestras etc.), ele poderá ter implicações negativas na sua prática pedagógica intercultural, apresentando dificuldades em investigar, compreender e relacionar os saberes culturais dos estudantes com os conhecimentos científicos e, com isso, tornar-se um mediador cultural por meio do diálogo.

Nosso próximo passo será a reelaboração e oferta de um curso de formação de professores para lidar com a diversidade cultural nas salas de aula de ciências pela Pró-reitora de Extensão Universitária (PROEX-UEFS) que vem sendo ofertado desde 2009, de modo a incluir professores da Educação Infantil e Anos Iniciais da Educação Fundamental que atuam no ensino de ciências naturais da educação Básica. Um curso que envolverá a etnobiologia, a história e a filosofia da ciência como forma de auxiliar os professores de ciências no desenvolvimento da competência intercultural, especialmente no que tange ao entendimento da ciência como atividade cultural dos cientistas que pode e deve dialogar com as culturas dos estudantes, sendo preciso para isto investiga-las e compreendê-las, bem como na elaboração e utilização de estratégias de ensino que facilitem as relações dialógicas, particularmente de comunidades tradicionais, cujos saberes frequentemente são ignorados e/ou discriminados nas salas de aula.

Por último ressaltamos nossa compreensão de que a formação do professor para o estabelecimento do diálogo intercultural não é uma tarefa fácil e não acontece da noite para o dia, mas sim um processo lento e complexo que envolve muito tempo, consciência pessoal e coletiva, dentro dos universos culturais das escolas e academias em trabalhos que sejam colaborativos e dinâmicos, não existindo, portanto, fórmulas, manuais, caminhos que sejam únicos, dada as subjetividades que são próprias da existência humana.

\section{REFERÊNCIAS}

ABD-EL-KHALICK, F.; LEDERMAN, N. Lederman. Improving science teachers' conceptions of nature of science: a critical review of the literature. International Journal of Science Education, v. 22, n. 7, p. 665-701, 2000 
BAPTISTA, G. C. S. Importância da demarcação de saberes no ensino de ciências para sociedades tradicionais. Ciência \& Educação, v. 16, n. 3, p. 679-694, 2010.

BAPTISTA, G. C. S. Um enfoque etnobiológico na formação do professor de ciências sensível à diversidade cultural: estudo de caso. Ciência \& Educação, v. 21, n. 3, p. 585-603, 2015.

BAPTISTA, G. C. S.; ARAUJO, G. M. Desenvolvimento para a competência intercultural na formação do professor de biologia pelas práticas da etnobiologia. Gaia Scientia, v. 12, n. 2, p. 76-88, 2018.

BARDIN, L. 1977. Análise de Conteúdo, Lisboa: Edições 70, p. 229.

BISPO, M. das G. de S.; BAPTISTA, G. C. S. Como os professores de biologia concebem a diversidade cultural: influências para o diálogo intercultural e proposta para a formação docente. Gaia Scientia, v. 13, n. 2, p. 48-63, 2019.

BOHM, D. On dialogue. Routledge, 2013.

BRASIL. Ministério da Saúde. Conselho Nacional de Saúde. Resolução número 466. Brasília: Ministério da Saúde, 2012.

CANDAU, V. M. F. Diferenças culturais, interculturalidade e educação em direitos humanos. Educação \& Sociedade, v. 33, n. 118, p. 235-250, 2012.

CANEN, A; XAVIER, G. P. de M. Formação continuada de professores para a diversidade cultural: ênfases, silêncios e perspectivas. Revista Brasileira de Educação, v. 16, n. 48, p. 641-813, 2011.

COBERN, W. W. Worldview, culture, and science education. Science Education International, v. 5, n. 4, p. $5-8,1994$

CREPALDE, R. S., AGUIAR, O. G. Abordagem intercultural na educação em ciências: da energia pensada à energia vivida. Educação em Revista, v. 30, n.3, p. 43-61, 2014.

CRESWELL, J. W. Projeto de pesquisa: métodos qualitativo, quantitativo e misto. $3^{\mathrm{a}}$ ed. Porto Alegre: ArtMed, 2010.

DIMITROV, D.; HAQUE, A. Intercultural teaching competence: a multi-disciplinary model for instructor reflection. Intercultural Education, v. 27, n. 5, p. 437-456, 2016.

FREIRE, P. Pedagogia do Oprimido, 17ª . ed. Rio de Janeiro, Paz e Terra, 1987, p. 107.

GEERTZ, C. Interpretação das Culturas. São Paulo: LTC, 1989.

GIL-PÉREZ, D.; VILCHES, A. inmersión en la cultura científica para la toma de decisiones ¿necesidad o mito? Revista Eureka sobre Enseñanza y Divulgación de las Ciencias, v. 2, n. 3, p. 302-329, 2005.

LOPES, A. R. C. Pluralismo cultural em políticas de currículo nacional. In: MOREIRA, A. F. B. (Org.). Currículo: políticas e práticas. Campinas: Papirus, p. 59-80, 1999.

PIZZI, L. C. V.; ALVES, J. C. da P. Currículo, cultura escolar e disciplinamento. Espaço do currículo, v.3, n.1, p.296-304, 2010.

POSEY, D. A. Etnobiologia: teoria e prática. In: RIBEIRO, D. (Ed.). Suma etnológica brasileira. 3. ed. Petrópolis: Vozes, v. 1. p. 1-15, 1997.

RAMÍREZ, T. El rol docente-investigador en Venezuela ¿Mito o realidad? Caracas: Ed. Núcleo de investigaciones filosóficas del IPC, 1995, 62 p.

SCHÖN, D. A. Formar professores como profissionais reflexivos. In: NÓVOA, António (Org.). Os professores e sua formação. Lisboa - Portugal: Dom Quixote, 1992.

SERCU, L. The foreign language and intercultural competence teacher: the acquisition of a new professional identity. Intercultural Education, v.17, n 1, p. 55-72, 2006.

SUCIU, M. C.; NEAGU, A. M.; MATEESCU, L. M. A perspective of intercultural dialogue in education. SEA: Practical Application of Science, v. 2, n. 3, p. 631-636, 2014.

TEO, W. T. Different perspectives of cultural mediation: implications for the research design on studies examining its effect on students' cognition. Cultural Studies of Science Education, v. 8, p. 295-305, 2013.

VASCONCELOS, C.; PRAIA, J. F.; ALMEIDA, L. S. Teorias de aprendizagem e o ensino/aprendizagem das ciências: da instrução à aprendizagem. Psicologia escolar e educacional, v. 7, n. 1, p. 11-19, 2003.

VIECHENESKI, J. P.; CARLETTO, M. Por que e para quê ensinar ciências para crianças. Revista do ensino de Ciência e Tecnologia, v. 6, n. 2, p. 213-227, 2013.

VILELA-RIBEIRO, E. B; BENITE, A. M. C. Concepções sobre natureza da ciência e ensino de ciências: um estudo das interações discursivas em um Núcleo de Pesquisa em Ensino. Revista Brasileira de Pesquisa em Educação em Ciências, v. 9, n.1, p. 1-21, 2009.

VOGT, A.C. Espiral da cultura científica. Com Ciência, Campinas. Atualizado em 10/07/2003. Disponível em: <http://www.comciencia.br/reportagens/cultura/cultura01.shtml>. Acesso em: 15 de maio de 2019. 